\title{
Avoiding philosophy as a trump-card in sociological writing. A study from the discourse of evidence-based healthcare
}

\author{
Benet Reid
}

\begin{tabular}{|c|c|}
\hline Date of deposit & 12052017 \\
\hline Document version & Author's accepted manuscript \\
\hline Access rights & $\begin{array}{l}\text { (c) Macmillan Publishers Ltd } 2017 \text {. This work has been made } \\
\text { available online in accordance with the publisher's policies. This is } \\
\text { the author created accepted version manuscript following peer } \\
\text { review and as such may differ slightly from the final published } \\
\text { version. }\end{array}$ \\
\hline $\begin{array}{l}\text { Citation for } \\
\text { published version }\end{array}$ & $\begin{array}{l}\text { Reid, B. (2017). Avoiding philosophy as a trump-card in } \\
\text { sociological writing. A study from the discourse of evidence-based } \\
\text { healthcare. Social Theory and Health }\end{array}$ \\
\hline $\begin{array}{l}\text { Link to published } \\
\text { version }\end{array}$ & https://doi.org/ 10.1057/s41285-017-0033-6 \\
\hline
\end{tabular}

Full metadata for this item is available in St Andrews Research

Repository at: https://research-repository.st-andrews.ac.uk/

\section{St Andrews Research Repository}




\title{
Avoiding philosophy as a trump-card in sociological writing. A study from the discourse of evidence-based healthcare.
}

\begin{abstract}
.
In this article I explore a situation where health sociologists encounter pure-philosophical reasoning in the fabric of social life. Accounts of the relationship between philosophy and sociology tend to be framed in abstract theory, so there is a need for practical ways to anchor philosophical reasoning in sociological writing. I consider the use of philosophies as strategic tools for socially-grounded understanding, rather than rhetorical trump-cards which bypass socio-political questions. I present my understanding in two stages: first, I discuss my example topic of Evidence-Based Healthcare (EBHC), reviewing some philosophical contributions by writers in that discourse. These niche-writings I contextualise briefly in relation to other academic meetings between philosophy and sociology. Second, I offer three philosophical perspectives on the topic of EBHC, and outline their significance for understanding it sociologically. I conclude that to navigate the difficult ground where philosophy and sociology meet, sociologists can entrain pure-philosophical argumentation to the purpose of critical, socially-situated understandings.
\end{abstract}

Keywords: philosophy, social theory, EBHC, health, theoretical methods.

\section{Introduction}

The disciplines of sociology and philosophy are bound to overlap and intersect: after all, they are both for investigating and understanding the experiences of people in the world. As Chernilo (2015) has noted, they are often imagined in contradistinction rather than in mutual support. Differences in disciplinary conventions over theory, and imperatives towards engagement with issues designated as 'real', may encourage social theorists (particularly in the field of health) to reflect upon the strategic uses they make 
of pure-philosophical reasoning in sociological analyses. In this article I draw upon a recent sociological study of Evidence-based Healthcare (EBHC), in which I found dissonance and tension between socialpolitical and pure-philosophical approaches to explanation.

I describe this tension as it appears in sociologies of EBHC, and contextualise it by noting some other recent expressions of perceived conflict between sociology and philosophy. I do not attempt to resolve this discord, perhaps I even add to it when reporting three further pure-philosophical observations of my own on the topic of EBHC: but I suggest that these observations are useful for their sociological rather than merely pure-philosophical significance. In cases where philosophy is a major theme in health policy discourse, there is a sense in which everybody who participates (doctors, nurses, policy-makers) becomes a philosopher, and other objectives can be submerged. Sociologists in particular, I think, are positioned in a way that makes them susceptible to losing sight of what is essentially sociological in their endeavours.

A temptation can arise for sociologists to approach philosophical problems as ends-in-themselves or ways to bypass or exonerate questions of sociological interest, but also ways to avoid doing so and to advance the case for social-sociology. Here I unfold a response to this challenge, which I found useful for analysing EBHC. EBHC has become a densely-theoretical topic, and a good part of the article is spent making its philosophical transactions accessible to the unfamiliar reader. By looking at EBHC in detail, I turn away from the abstract (philosophical) synergies and interferences between philosophy and sociology, and seek ways to channel philosophical diversions back towards sociological uses. I do not look to deconstruct the philosophy-sociology dyad theoretically, but to work it towards a social-logical end-point, which (at least in the context of EBHC) has remained unexplored. This leads towards a sociology which, while it is rather self-consciously concerned to remain 'critical', I see as a positive move towards understanding social phenomena in ways which retain a central focus on social conduct.

\section{EBHC: philosophy in clinical writing.}

There are plentiful, broadly similar definitions of EBHC - French (2002), for example, discussed fourteen definitions, which had all fallen into disuse. I define it by saying that the discourse around EBHC primarily 
asks how grand-scale statistical Evidence, derived from experimental populations, is to be reconciled with the expertise which clinicians develop through their personal practice and their dealings with patients. This issue is the basis of a debate which, for over 20 years, has been influential in maintaining modern healthcare as a trusted and powerful social institution. To study EBHC sociologically is therefore to study the mechanisms of power and knowledge-renewal in health and healthcare, so sociologists should pay attention to this topic (Timmermans 2013).

The literary discourse of EBHC began in earnest in 1992 (see EBMWG 1992 - although there were earlier precursors for it, eg. Haynes et al 1983, Guyatt et al 1988). It is a literature in which philosophical excursions are commonplace. The EBMWG (1992:2420) proposed EBHC as a means to supplement and supplant first-person expertise with clinical-trial data in medicine. They claimed for this event the status of a Kuhnian Paradigm Shift in medical science, a claim which was indignantly rebutted (see eg. Couto 1998, Sehon and Stanley 2003). Clinician-writers who quarrelled bitterly over EBHC in its early stages differed over practicalities as much as over theoretical precision: but pieces like Grahame-Smith's (1995) satirical dialogue (between a wise Socrates and a character smitten with admiration for EBHC, Enthusiasticus Meta-Analyticus), illustrate how readily the rhetoric of this debate could turn quasiphilosophical.

Much was done to extend the philosophical possibilities of EBHC-debate by one clinician-philosopher, Ross Upshur. At first, Upshur tried to find a secure philosophical basis on which to resolve the dispute over EBHC. In Upshur (1997), he proposed CS Peirce's 'abductive pragmatism' as a way to work towards the recognition of both experiential and research-based knowledge as having value. In Upshur (1999) he referenced Gadamerian hermeneutics and Bayesian probability theory, imagining the clinician as an interpretive agent, mediating between different sources of information. In Upshur (2000) his theoretical concern switched to fallibilism, and he lamented the polemical nature of the debate over EBHC, an issue he maintained was 'quintessentially philosophical' (2000:93). Upshur's philosophical dexterity afforded him, to begin with, a neutral and circumspect position in this debate. 
Upshur et al (2001) moved towards dissent against EBHC, proposing a typology of research which made space for qualitative, personal and narrative forms of evidence. In Upshur (2002) he identified EBHC with foundationalism, and all the pitfalls such a philosophy entails. Upshur and Tracy (2004) confronted EBHC with four problematic cases from practice, concluding on the necessity of protecting embodied clinical expertise. Finally, Upshur (2005) was unreservedly critical of EBHC, and expressed the disillusioned view that it is 'not a philosophical doctrine' (2005:477). Although he could no longer find philosophical value in EBHC itself, Upshur had done much to guarantee the place of analytic philosophy in the discourses around EBHC. This helped lay a foundation for the expansion of EBHC debates beyond the narrow context designated by the mutually-distinct clinical spheres of 'research' and 'practice'.

\section{Philosophical sociologies of EBHC.}

Health sociologists are heavily involved in debates over EBHC, whether positioned within it (trying to resolve its problems - eg. Green \& Britten 1998, Popay et al 1998) or outside it (commenting upon its interpretation - eg. Armstrong 2002, McLaughlin 2001). In sociological accounts, the tension between philosophical analyses and other types of understandings, noticeable in Ross Upshur's trajectory through the debate, has continued to be played out. Saarni and Gylling's (2004) querying of EBHC as 'politics disguised as science', instantiates the conceptual antagonism between (scientific) knowledge conceived as pure/clean, and politics conceived as dirty. Consider these two early sociological accounts of EBHC: Stephen Harrison's (1998) political-economic analysis, and Judith Green’s (2000) article on 'epistemology, evidence and experience'.

Harrison's (1998) view was that while EBHC made sense politically as a vehicle to engage doctors in the rationing of healthcare, it did not make sense philosophically. Harrison identified some theoreticalphilosophical problems which led him to a direct critique of EBHC, which he says 'amounts to the assumption of consensus where there is none' (1998:26). There is some unease between the political (social) and theoretical (philosophical) sides of his argument. Primarily, Harrison's (1998) is a sociopolitical analysis, but one in which pure-theoretical reasoning has the power to eclipse political reasoning. 
EBHC fails the test of philosophical clarity: therefore it fails absolutely, and Harrison (like Upshur) aligned himself in dissent against EBHC, because of its theoretical unsophistication.

Green (2000) began her analysis of EBHC with the conceptual construction of Evidence as a route to clinical decision-making. She found that different disciplines and practices generate different evidential cultures which, being constructed in mutual distinction, are incompatible. Consequently the issue of evidence, rather than facilitating consensus she says, works to enrich and intensify political conflicts within healthcare. Emphasising the philosophical nature of Evidence disputes helps Green (2000), like Upshur in his earlier writings, to maintain rhetorical neutrality in relation to the controversies of EBHC. While her technique draws upon a philosophical aesthetic, her explicit argument is that Evidence itself is something whose essence and energy is not in pure knowledge, but in social politics.

These two benchmark sociology-of-EBHC pieces carry forward and develop Upshur's dilemma - an ambivalence and incompatibility between political and philosophical reasoning. Although both authors acknowledge this ambivalence to some extent, its dichotomous construction remains little explored. The tension between social-political and pure-philosophical styles of thought is discernible in other sociological writing on EBHC. There are some cases to briefly discuss where this tension became more pronounced, and philosophical analysis was more explicitly put at the forefront of sociological arguments.

\section{Using philosophy as a solution for sociology.}

Cronje and Fullan (2003), for instance, present a narrative of EBHC constituted in pure-philosophy, as being an orchestrated effort to forge a new model of collective rationality for health practice. They draw upon the philosophies of Harold Brown (for classical rationality) and Jürgen Habermas (for dynamic negotiation and the 'ideal speech situation') to outline the conditions of this 'cooperative search for the truth' (2003:363). Finding analogues of these philosophies in the tenets of EBHC, they present EBHC as a process for dealing with philosophical problems pragmatically. Their conclusion - that the test of any standard of rationality is 'its compatibility with the pragmatic needs of its community' (2003:365) brushes against socio-political concerns. But in defining EBHC as a consensual and theoretical rather than 
a conflictual and enacted phenomenon, they imagine the debate over EBHC as something thought-through in serene rationality, narrowing the scope for critical social comment.

It could indeed be sociologically helpful to conceive healthcare guided by a unified communal consciousness, moving teleologically towards a rational future, but this does not make space to model modern health institutions as differentiated and segmented (McNeil et al 2013), nor as embedded in their social context of global marketplaces (Erikson 2012), health rationing (Smith et al 2014) and neo-liberal capitalist governance (Peacock et al 2014) which are key socio-political concerns. Besides, the exchanges through the 1990s between the colleagues of David Sackett, writing in support of EBHC (eg. Sackett and Cook 1994, Sackett and Rosenberg 1995, Sackett and Straus 1998), and those who wrote polemically against EBHC (eg. Miles 1995, Miles et al 1997, Miles et al 1998) for examples, show that this debate has often been combative and at times vitriolic. The analytic philosopher may turn away from this sociallylived history and focus on pure-theoretical issues judged in hindsight to have been relevant, but for sociologists an appreciation of the confrontations and the messiness of EBHC-discourse is necessary to understanding the dynamics of EBHC as a social phenomenon.

Kelly and Moore (2012) focus also on the rationalities of EBHC. They derive theoretical authority from the rationalist and empiricist philosophies of Kant and Hume. They explain that pursuing a philosophical resolution to debates of EBHC, while it might seem far-removed from the actualities of health policy decision-making, helps to 'illuminate the real tensions' (2012:16, my emphasis) experienced by policymakers grappling with the difficulties of evidence application. The act of connecting EBHC to this 'very old intellectual divide, well-known to Enlightenment philosophers' (2012:16) they see as a means of getting EBHC 'off the hook' of accusations of philosophical naivety (2012:9). Like Cronje and Fullan (2003), their analysis is highly intelligent, but sociologically problematic.

Critical engagement with Kelly and Moore's (2012) exposition requires considerable philosophical capacity: to decide whether their distinction between real things and observations of things is robust, whether their elision between sense-data and empirical data is faithful to the philosophies of Hume and 
Kant, whether deduction can be cleanly excluded from clinic-based reason, and induction from evidencebased reason, as they suggest. My concern here is not to pursue these questions in the realm of analytic philosophy, but to observe their outcome: the use of pure-philosophical strategy to show that the problems of EBHC are 'quintessentially and inevitably difficult' (2012:15), by implication that the debate over EBHC is legitimate, and by suggestion that EBHC itself is a sincere attempt to solve the problems it constitutes as real (rather than, say, a rhetorical technology which forestalls other criticisms of modern healthcare, or whatever other socio-political ends it might mesh with).

Alongside these philosophical pieces which support EBHC compare Goldenberg (2006), who draws upon feminist and post-positivist philosophies of science to build a critique. The advent of EBHC, she says, shows that the lessons of such philosophies have not been well-learnt. She challenges the foundationalism of EBHC using the phenomenology of experience to differentiate between a masculine, objectivist science and a feminine, embodied and contextually-situated science which would, she argues, provide a more secure platform for evidence-basedness. She concludes with a discussion of politics in distinction from science and philosophy: 'political issues are not resolved [by EBHC] but merely disguised in technocratic consideration and language', she writes (2006:2630).

Goldenberg's (2006) appraisal of EBHC returns then to matters of theory, as she seeks a way to make the politics of EBHC more visible and accountable through a philosophical re-imagining of science. She is explicitly aware of the disjuncture between pure-philosophical and socio-political styles of explanation, but while recognising the embeddedness of healthcare policy in social and political structures, she remains reliant upon a theoretical-philosophical argument to mount her critique of EBHC. The key consequence of Goldenberg's (2006) analysis then is that the problems of EBHC can best be understood, even resolved, by a sojourn into abstract theory. So once again, the distinction between social-politics and philosophy is something drawn upon and acknowledged, but not critically scrutinised.

In these pieces of technically-accomplished writing, one can perceive unease between endeavours of socio-political argumentation and pure-philosophical analysis. All are explicit about their use of 
philosophical reasoning, but rather than draw out the problematics of inscribing a boundary between philosophy and political-sociology they work around this tension, ultimately using philosophy as a vehicle to pass over issues of sociological interest, or as a means to try to ameliorate the dispute over EBHC. Their philosophical strategies work as something of a trump-card, a way to offset social dilemmas through sublimation onto a philosophical plane where rights and wrongs can be more clearly stipulated. Philosophy becomes sacred, and social-politics profane (just as statistical Evidence and clinic-based reason were alternately made sacred and profane by clinical EBHC writers).

To be sure, philosophical debates are of interest to social theorists in general and for their own sake. But also, sociologists can ask what political interests are being served when a debate originally over the practicalities of clinical decision-making, becomes ever more intensely and abstractly theorised. Where the debate over EBHC becomes pure-philosophical, sociologists are obliged to engage with it, but also to retain sensitivity to its socio-political grounding. The recurrent tension between philosophy and social politics is something for sociologists to inquire about even while caught within it. They can analyse both sides: the sacred theoretical, and the profane political, and their interaction. Before I present my suggestion for how to approach this problem in EBHC, I shall briefly show that it is not unique to that topic. Others have found it a difficult relationship too.

\section{Philosophical sociology and sociological philosophy.}

Randall Collins has sceptically noted, concerning philosophy, that it moves always so as to claim the greatest generality and importance, and as such occupies the sacred realm of truth by virtue of its 'detachment from ordinary concerns' (2009:19). In different sociological contexts, this precarious sanctity of philosophical knowledge can be discerned. Concerning bioethics, for instance, Haimes and Williams (2007) looked for ways to facilitate cooperation between sociologists and ethicists generally. They acknowledge theoretical and practical disparities and linkages between the philosophical and sociological disciplines. To simplify: ethics is at risk of disconnection from the lived realities experienced by people within social institutions, and sociology cannot be just empirical and descriptive, but must fully 
engage in theoretical debates over values and norms if it is to be socially useful. The two disciplines need each other, but appear frustratingly divided.

Haimes and Williams' (2007) tentative solution is to offer phronesis - a philosophical idea originating from Aristotle - as a way to make a bridge between ethicists and sociologists. Phronesis keeps philosophy contextually-grounded, and gives sociology an impetus towards theoretical clarity. (Another philosophy which has been suggested to accomplish this reconciliation is pragmatism - see Gross 2003). A comparison with Petersen (2013) can highlight the hierarchical nature of these propositions to unite sociology and philosophy. Whereas Haimes and Williams' (2007) make recourse to a philosophical idea, Petersen (2007) puts sociology resolutely first, proposing various sociological genres as a tool-kit for building a new practical ethics away from philosophy. As he definitively puts it, 'the time for 'saving' or reforming bioethics has passed' (2013:268).

Another approach to present philosophy as a general solution to whatever problems are perceived to afflict sociology. Mario Bunge's oeuvre, and particularly his book The Sociology-Philosophy Connection (Bunge 1999) illustrates this quite well. Bunge sees sociology as a discipline in poor health, and purephilosophy in the role of doctor. By looking for the purely-philosophical problems hidden within sociology, he looks to bring proper theoretical clarity to sociological ideas. He is forthright in his criticism for philosophers who pronounce upon sociology without engaging with it (1999:1), and hopes, by discovering the philosophical content within sociology, to make sociology theoretically intelligible. But he implies that in order to be intelligible, sociology must become philosophical.

At least Bunge sees value, albeit not fully realised, in sociology. Another philosopher, Martin Kusch, expressed a similar sense of frustration at analytic philosophers' reluctance to take seriously his interest in sociology. 'Why', a colleague had asked him, did he waste his time on such a 'dubious' field of study? (Kusch 1999:651). He was to edit a collection of writings (Kusch 2000) making sociological analyses of philosophy, towards an argument that the history of philosophy is not a history just of ideas floating freely in the realm of pure knowledge, uncontaminated by the contingencies of social engagement. Instead the 
history of philosophy, like the history of science, is a social history - embedded in strategy and political exchange. Kusch's (2000) hypothesis is that the content of philosophical ideas can be understood in terms of the social conditions which produce them.

The climate of these proceedings mirrors the bifurcation in EBHC-debate between philosophical and social styles of explanation. It may also resonate with other dichotomised disputes there between research evidence and expertise, quantitative and qualitative methods, simplicity and complexity, place and placelessness, purity and impurity. The analysis I shortly present is a refusal to adjudicate in such disputes. Clinicians are bound to disagree over the primacy of different knowledge forms as justification for the things they do. Philosophers and social theorists may continue to arrange themselves around questions of theoretical priority, and they are free to do so.

For the sociologist interested in EBHC however, Upshur's dilemma creates a fork-in-the-road. They are confronted with philosophy, being such a powerful theme in evidence-basedness discourse, which they must reconcile with their identity as sociologists. They may become suspicious of accounts of philosophical sociology framed in abstract theory, as even those sympathetic to sociology are likely to have a philosophical inflection (eg. Chernilo 2014). They require, therefore, a practical means to anchor philosophical reasoning in sociological writing. To show how I envisage this, I present three philosophical observations I have made on EBHC whose value I think lies in their sociological use ${ }^{1}$.

\section{Three philosophical-social analyses of EBHC.}

\section{i. The positivism/realism inconsistency.}

EBHC is associated with the philosophical idea of positivism (Djulbegovic et al 2009). An alternative empiricist philosophy to positivism is critical realism (see Sayer 1999), which is of relevance because of

\footnotetext{
${ }^{1}$ Moving into a pure-philosophical realm elicits a slightly more direct, possibly abrasive writing style, for which I apologise.
} 
the exclusion in EBHC of 'pathophysiologic rationale', or explanatory causal mechanisms, from clinical reasoning ${ }^{2}$. In critical realism the necessity is insisted upon of invoking causal mechanisms (analogous to pathophysiologic rationale) as a path to explanation. Such mechanisms are not directly observable, and so are classed, under strict positivism (and EBHC), as nonsense. A brief thought-experiment, looking at the reasoning underlying the randomised-controlled trial ( $\mathrm{RCT}$ - the totemic research method of $\mathrm{EBHC}^{3}$ ), clarifies the relevance of this problem.

Imagine an RCT in which a population with health problem $\mathrm{X}$ is divided randomly into two halves, to which interventions A or B are blindly administered. Observation of the difference in change between the two groups enables a causal influence to be attributed, or not, to intervention A compared to intervention B for treating X. The EBHC-advocate, eschewing pathophysiologic rationale, cannot advance an account of the mechanism by which A is effective, but they must use a concept of causation if they are to claim that the trial has the capacity to generate meaning. This replicates the realist critique of positivism: that it relies tacitly upon causal principles which are explicitly renounced in its doctrine. The EBHC-advocate must simultaneously follow positivist (causation-denying) and realist (causation-invoking) epistemological schemes.

In writing on EBHC, this philosophical difficulty is not often brought into plain sight. It is sometimes noted, however, that EBHC depends on causal suppositions in order to decide which interventions to test by RCT. This predicament has led to some elaborate sarcasm. For example, Smith and Pell (2003:145961) presented a systematic review of RCTs on 'parachute use to prevent death and major trauma related to gravitational challenge'. They invite protagonists of EBHC to follow their principles to logical conclusion, and participate in a randomised trial of parachute use. There is plenty going on there for the

\footnotetext{
${ }^{2}$ see EBMWG (1992), and eg. Tonelli $(1998,2006)$ for critical comment.

${ }^{3}$ Oakley (1998) gives a sociological history of the RCT. For a medical perspective see Deveraux and Yusuf (2003).
} 
sociologist to grapple with, but the philosophical point of interest is the difficulty of constructing an afterthe-fact account of EBHC which is both coherent and faithful to the arguments of EBHC-advocates.

What is to be inferred sociologically from this philosophical difficulty with EBHC? It is not that EBHC is philosophically lacking and therefore no good, but rather that philosophical precision was not required for EBHC to become controversial and influential. In fact, the philosophical issue of causation became a point around which participants in the EBHC-debate could arrange themselves in mutual distinction, and therefore a strength of EBHC, sociologically speaking. A philosophical resolution (if it were possible) might even be unwelcome for those who participate in continued theoretical arguments around EBHC, meaning they subsequently had less to disagree about. It is also interesting (and invites exploration) that writers on EBHC would persist in presenting philosophical analysis as if it did have the potential to definitively resolve the disputes of EBHC, leading to consensus, rather than to elaborate upon further points of difference.

\section{ii. The Hermeneutic Programme.}

Much writing on EBHC rests on the assumption that EBHC itself is inherently foundationalist, and that therefore all opposition to EBHC must be inherently anti-foundationalist, relativist or even 'post-modern' (see Holmes et al 2006, and associated articles). One way ${ }^{4}$ to show that this is not the case is by considering the hermeneutic programme. In EBHC-writing, hermeneutics arises as a way of dissociating from evidence-basedness. For example, Gibson and Martin (2003:351) use the term in opposition to 'mathematical' evidence. McKenna et al (2004:372) use it in conjunction with 'phenomenology' to characterise health research conducted at the qualitative end of the method spectrum. Upshur et al (2001:93) use 'hermeneutic dimensions' to connect to a 'concern with the interpretation of meaning rather than quantities or properties of objects' (implying that quantities or properties of objects are not themselves concerned with meaning).

\footnotetext{
${ }^{4}$ There are other ways to show this, but I have not space for them here.
} 
To make such connections as these is reasonable. After all, hermeneutics has come often to be used as a catch-all term for philosophies and methodologies thought to be obscure and non-scientific. What authors on EBHC do not normally acknowledge is a more fundamental way in which EBHC is conservatively and obviously hermeneutic. Hermeneutics as the study of texts has its historical origins in the interpretation of biblical scripture (see Thiselton 2009). Although references to the religious zealotry of EBHC are frequent in the discourse, (eg. Greenhalgh's (2006:xiii) request not to be seen 'as an evangelist for the gospel according to EBHC') this is not the sense in which I invoke the term. EBHC is hermeneutic simply because it is concerned with knowledge transmission through the act of reading.

See for example Rosenberg and Donald's (1995) guide to clinical literature use. They describe a process of literature searching, in which important supporting actors are computer technologies and librarians; appraisal, in which the individual clinician takes a role as a careful reader; and implementation, in which the clinician returns to the social stage, and by demonstrating to colleagues their hermeneutic skill, institutes a clinical action. The clinician is configured as a reader - not a reader of bodies, or patients, or clinical scenarios (cf. Leder 1990), but a reader of literature. Their hermeneutic work takes place not at the bedside with the stethoscope, but in the library with the database. The path from library back to clinic is unproblematic, and the clinical act is one of heroic exegesis - 'sticking to the letter of hallowed texts' (to use the words of Zygmunt Bauman (2001:23)).

As an ideal based around texts as vectors for knowledge and determinants of action, the epistemological character of EBHC is hermeneutic. Mykhalovskiy (2003) draws attention to texts as the fundamental technology of EBHC, and the act of reading as its central practice: it is a 'technology of applied reading' (2003:341) which 'centers (sic) on and is enabled by texts' (2003:332), and can achieve 'immanent normalisation' by 'hooking readers into a common system of representation' (2003:338). Reading becomes a process of 'rehabilitation' (2003:341) for doctors, and their reading practices constituted as 'an object for intervention' (2003:343). In this ontological inversion, the doctor has become a patient 
rather than the heroic figure imagined by Rosenberg and Donald (1995), but still a patient who sees themselves as ill and desires health, achievable through disciplined reading.

The ease with which a principle of hermeneutics can be applied to EBHC causes philosophical trouble if EBHC is held to depend inalienably upon principles of foundationalism, naturalism and empiricism thought incompatible with the hermeneutic tradition. If EBHC is hermeneutically based on socialconventional acts of correct reading, it is more difficult to think of it as natural-scientific, an idea central to the rhetoric of both EBHC-advocacy and detraction. Here lies the sociological significance of the hermeneutic programme: to claim that EBHC expresses an anti-foundationalist philosophy is reasonably straightforward, yet it is not attended to in EBHC-writing. Why is it not attended to? Most likely because it does not fit the terms of the debate as structured by social and political factors, and by institutional convention.

\section{iii. Circularity and the Evidence Paradox.}

In EBHC-debate, there is controversy over the issue of providing evidence-for-Evidence. This can be assessed with reference to Harry Collins' concept of 'experimenter's regress' (Collins 1992). The experimenter's regress encapsulates the circular relationship between empirical procedures and scientific outcomes. In one of Collins' exemplars, the existence (or non-existence) of gravitational (G) waves is shown to coincide with the validation of apparatus used to attempt their detection (Collins 1998). This means that one cannot know whether G-waves exist except by detecting them (or not), but one cannot know whether one's means of detecting G-waves is reliable, except by first knowing the correct result (whether or not G-waves exist). This crisis can be resolved only through the influence of secondary factors: theories as to whether G-waves 'should' exist, or other reasons to trust the apparatus (see also Kusch 2012).

The experimenter's regress can be rephrased to make clear its relevance to EBHC. In empirical science, experimenters are not normally required to provide a general justification for empirical method. For the most part, scientists work within cultures of experimentation (Fleck 1979) without being asked to justify 
experiments in general terms. But if the experimental method is called to account, then it can only be justified by means other than the experimental method. No experiment can be done which itself demonstrates the legitimacy of experiments, because this would set up a circularity of reasoning. Other reasons - philosophical, political or theological ones, perhaps - must be given in support of the conviction that experiments sui generis yield knowledge.

In EBHC-discourse, the issue of evidence for Evidence is discussed. EBHC is, evidently, an unusual case in which justification is required but on pain of circularity, Evidence-Based methods cannot be advanced in their own defence. This difficulty goes unnoticed in the literature on EBHC. EBHC-advocates from EBMWG (1992) onwards (eg. Djulbegovic et al 2000, Grol and Wensing 2004, Jensen et al 2005, Schreiber and Stern 2005) have lamented the absence of comparative trials which would support their cause. Critics, conversely, seize upon this absence to claim that EBHC is inconsistent, and a failure to itself (Charlton 1997, Goodman 1999, French 2002, Arndt and Bigelow 2009).

Consider Norman (1999) who presents a critique of EBHC which itself takes an evidence-based approach. He summarises his argument as follows:

'It seems reasonable that practitioners who keep up to date are going to deliver better care. Do we need the burden of numerical proof to support such a self-evidently correct assumption? The answer is, of course, 'Yes'. EBM, if it has done nothing else, has made us wary of accepting unsubstantiated claims of efficacy, regardless of how plausible they may appear. Regrettably, the claims of EBM fall into the same category.'

Norman 1999:144.

The 'of course' in this passage signals a problem being silenced. Because of the circularity problem, an Evidence-Based argument could not be used to support Evidence-Basedness, even if it were practically possible to produce data for it. Norman's (1999) argument against EBHC is based on an evidence-based ideal. It is an acceptance of EBHC in order to reject it. 
Without commenting evaluatively on Collins' theory of experimenter's regress, I contend that this philosophical approach (and the broader issue of circularity) has an immediate application for sociologists of EBHC. EBHC-advocates cannot provide EBHC-style evidence for their beliefs: the presentation of such evidence would put them in a position of circularity, under which the dynamic of EBHC-discourse (literary exchange between sides conceived in opposition) would collapse. The debate around EBHC exists under this condition of paradox. It cannot be resolved in accordance with the conditions which sustain it. To keep going, it needs to have participants taking sides, and the structural inter-connectedness of those participants to remain hidden.

The sociological insight to be gained under these circumstances is this: it makes sense that the discourse around EBHC has been prolonged, repetitive and fractious, for it contains within it a theoretical and practical condition (of differentiation and disagreement) which more-or-less guarantees its perpetuation. Those within the discourse are constrained to think about 'evidence' in particular and incompatible ways. The irresolvability of these issues helps to explain their enduring capacity to stimulate debate, and therefore retain social influence. Once again, philosophy is useful to the sociologist: not to settle the debate on the terms established, but to facilitate a sociological perspective on how the debate about EBHC, as a set of contingent social behaviours, has been conducted.

\section{Discussion.}

The EBHC-debate has many philosophical dimensions. The three discussion points I have presented - the positivism/realism inconsistency, the hermeneutic programme, and the evidence paradox - I have chosen because they potentially have a different character to other philosophies offered by sociologists of EBHC. They are not ways to try to solve the arguments of EBHC, or to clean up the messiness of EBHC-debate by sweeping away its socio-political complexities, nor to re-define 'evidence', or whatever else philosophies of EBHC might have been (consciously or not) intended to achieve. It is also necessary to emphasise that they are open to philosophical challenge. People might criticise them (as philosophies) and offer alternative associated (sociological) interpretations. 
The above analyses draw attention to ways in which the disputes of EBHC are constructed and maintained as valid disputes. They expose the aspects of the debate which have been decided upon tacitly, by unspoken convention. They open up critical space to think about EBHC in ways different from those wellestablished in the discourse. They indulge in pure-philosophy, not for its own sake but in the hope of eliciting sociological insight. I present them in the context of Upshur's dilemma: the question of whether the essence of EBHC-debate as social life is in pure thought, theoretical necessity, or in socio-political contingency. Sociological inferences about the political arrangement of participants in the debate can, I think, be 'read off', at least in principle, from the way they have conducted their arguments philosophically.

The argument from analysis by positivism/realism is not simply that EBHC is philosophically inconsistent: this can in 2016, I think, be taken as read. It is to observe that philosophical inconsistency in EBHC, while it has been seen as a philosophical (therefore absolute) weakness, is better seen as a sociological (relative) strength. Philosophical equivocation has allowed the debate over EBHC to flourish and proliferate. This means that there is something questionable about attempts to write consistent philosophies of EBHC in hindsight. They have the character of rhetoric, deployed in socio-political strategy to reinforce the terms of the debate as established, rather than to unsettle those terms. Sociologists can always be sceptical of such initiatives presented in terms of pure-philosophy, and ask what socio-political ends they serve.

The argument from the hermeneutic programme builds upon that from the positivist/realist inconsistency. It notes that EBHC-debate has been conducted under the conventional assumption that EBHC is basically foundationalist, and dissent to EBHC basically anti-foundationalist. The hermeneutic programme turns this dynamic inside out, and shows that EBHC can easily enough be read in quite different terms. The lack of any challenge to the conventional (philosophical) dichotomisations of EBHC debate is something the sociologist can look to investigate. Why have those terms gone unchallenged? The political motivation to challenge them may be lacking. What would it mean to say that the motivation to challenge the terms is lacking? Sociologically, it would mean to say that the major stakeholders in the 
EBHC-debate - clinicians, statisticians, health researchers, policy makers, pharmaceutical companies and so on - are broadly satisfied with the debate being choreographed as it has been.

The argument from the evidence paradox goes deeper into the mechanisms of the EBHC-debate as a socially-enacted phenomenon. People systematically occupy a variety of positions in this debate. Via the evidence paradox, sociologists can see broadly why this might be so. Each position is defensible only in relation to other positions, and underneath the (heartily fought) disputes of EBHC, there is tacit agreement on what issues are worth fighting about, and on the terms of opposition. Through their arguments, participants validate each other's positions even if - especially if - their conscious objectives are to attack each other. This is something the inquiring sociologist may have suspected anyway, but attention to the philosophical side of the debate clarifies the ideological mechanisms of collaboration underlying conflict.

\section{Conclusion.}

Philosophers Godin and Gingras (2002), in their critique of Collins' experimenter's regress, rather disdainfully advised sociologists to:

'content themselves with using the sociological concepts and tools of their trade instead of being trapped in philosophical debates for which they are often ill-equipped...'

Godin and Gingras 2002:150.

Sociologists, however, cannot avoid philosophy when it is woven into the fabric of social life (as it is with EBHC). Then they have no choice but to engage with apparently-pure philosophy, which is not just an important, but a fascinating aspect of debates on this topic. They might find themselves writing philosophy at the expense of writing sociology. To avoid this, sociologists can dictate the terms of their engagement with the philosophies of EBHC. They can protect the capacity of their discipline to be critical (reflexively instantiating the concerns of Boltanski and Thevenot, 1999) by maintaining a hermeneutic of suspicion (Gadamer 1984) towards philosophy as rhetoric. To philosophise - to seek clarity of thought through 
transcendental and abstracted presentations of truth - is, after all, a profoundly human thing to do. Nobody should be excluded from philosophy. Always though, it is a means of making particular arguments (and this is especially clear in fiercely-contested debates over knowledge-prioritisation in policy, like EBHC) persuasive, and therefore ultimately a socio-political technique.

For making sociological arguments about EBHC, philosophy must serve a pivotal role. It is indispensable if the sociologist is to convincingly analyse the terms of the EBHC debate, and seek out theoretical spaces to put those terms in question. In doing this, the sociologist can set the conditions for critical involvement, rather than joining in with the debate on terms already established. Without engaging the philosophical dimension, they cannot very well claim to understand how the debate structures and is structured by social interactions. It is very well to insist that EBHC is an expression of institutional power relations, but without suggesting how this debate could have been different, the mechanisms of power relations cannot so well be brought into view. Pure philosophy is therefore sociologically valuable when it allows different, unexpected thought-spaces to be made accessible.

\section{References.}

Armstrong D (2002). Clinical autonomy, individual and collective. The problem of changing doctors' behaviour. Social Science and Medicine 55:1771-7.

Arndt M and Bigelow B (2009). Evidence-based management in health care organisations. A cautionary note. Health Care Management Review 34(3):206-13.

Bauman Z and Tester K (2001). Conversations with Zygmunt Bauman. Cambridge: Polity Press.

Boltanksi L and Thévenot L (1999). The Sociology of Critical Capacity. European Journal of Social Theory 2(3):359-77.

Bunge M (1999). The sociology-philosophy connection. London: Transaction Publishers. 
Charlton B (1997). Restoring the balance. Evidence-based medicine put in its place. Journal of Evaluation in Clinical Practice 3(2):87-98.

Chernilo D (2014). The idea of philosophical sociology. The British Journal of Sociology 65(2):338-57

Collins HM (1992). Changing order: Replication and induction in scientific practice. University of Chicago Press.

Collins HM (1998). The meaning of data: open and closed evidential cultures in the search for gravitational waves. American Journal of Sociology 104(2); 293-338.

Collins R (2009). The sociology of philosophies. Cambridge, MA: Harvard University Press.

Couto J (1998). Evidence-based medicine: a Kuhnian perspective of a transvestite non-theory. Journal of Evaluation in Clinical Practice. 4(4); 267-75.

Cronje R and Fullan A (2003). Evidence-based medicine: toward a new definition of 'rational' medicine. health 7(3); 353-69.

Devereaux P and Yusuf S (2003). The evolution of the randomized controlled trial and its role in evidence-based decision making. Journal of Internal Medicine 254:105-13.

Djulbegovic B, Morris L and Lyman G (2000). Evidentiary challenges to evidence-based medicine. Journal of Evaluation in Clinical Practice 6(2):99-109.

Djulbegovic B, Guyatt G and Ashcroft R (2009). Epistemologic inquiries in evidence-based medicine. Cancer Control 16(2):158-68.

EBMWG (1992). Evidence-based medicine. A new approach to teaching the practice of medicine. JAMA 268(17):2420-5

Erikson S (2012). Global health business. The production and performativity of statistics in Sierra Leone and Germany. Medical Anthropology: Cross-cultural Studies in Health and Illness 31(4):367-84. 
Fleck L (1979). The genesis and development of a scientific fact. Chicago: University of Chicago Press.

French P (2002). What is the evidence on evidence-based nursing? An epistemological concern. Journal of Advanced Nursing 37(3):250-7.

Gadamer HG (1984). The hermeneutics of suspicion. Man and World 17 (3-4):313-23.

Gibson B and Martin D (2003). Qualitative research and evidence-based physiotherapy practice. Physiotherapy 89(6):350-58.

Godin B and Gingras Y (2002). The experimenters' regress: from skepticism to argumentation. Studies in History and Philosophy of Science Part A 33(1):133-48.

Goldenberg M (2006). On evidence and evidence-based medicine. Lessons from the philosophy of science. Social Science and Medicine 62(11):2621-32.

Goodman N (1999). Who will challenge evidence-based medicine? Journal of the Royal College of Physicians London. 33; 249-51.

Grahame-Smith D (1998). Evidence-based medicine. Challenging the orthodoxy. Journal of the Royal Society of Medicine 91(S35):7-11.

Green J (2000). Epistemology, evidence and experience: evidence based health care in the work of Accident Alliances. Sociology of Health and Illness 22(4):453-76.

Green J and Britten N (1998). Qualitative research and evidence based medicine. BMJ 316(7139):12302.

Greenhalgh T (2006). How to read a paper. The basics of evidence-based medicine. Chichester: WileyBlackwell.

Grol R and Wensing M (2004). What drives change? Barriers to and incentives for achieving evidencebased practice. Medical Journal of Australia 180(6):57. 
Gross N (2003). Richard Rorty's pragmatism: A case study in the sociology of ideas. Theory and Society 32(1):93-148.

Guyatt G, Sackett D, Adachi J, Roberts R, Chong J, Rosenbloom D and Keller J (1988). A clinician's guide for conducting randomized trials in individual patients. Canadian Medical Association Journal 139(6):497-503.

Haynes RB, Sackett D and Tugwell P (1983). Problems in the handling of clinical and research evidence by medical practitioners. Archives of Internal Medicine 143(10):1971-5.

Haimes E and Williams R (2007). Sociology, ethics, and the priority of the particular: learning from a case study of genetic deliberations. British Journal of Sociology 58(3), 457-476.

Harrison S (1998). The politics of evidence-based medicine in the United Kingdom. Policy and Politics $26(1) ; 15-31$.

Holmes D, Murray S, Perron A, Rail G (2006). Deconstructing the evidence-based discourse in health sciences. Truth, power and fascism. International Journal of Evidence-Based Healthcare 4(3):180-6.

Jensen P, Weersing R, Hoagwood K and Goldman E (2005). What is the evidence for evidence-based treatments? A hard look at our soft underbelly. Mental Health Services Research 7(1):53-74.

Kelly M and Moore T (2012). The judgement process in evidence-based medicine and health technology assessment. Social Theory and Health 10(1):1-19.

Kusch M (1999). Philosophy and the sociology of knowledge. Studies in the History and Philosophy of Science $30(4): 651-85$

Kusch M (2000 ed.). The sociology of philosophical knowledge. London: Kluwer Academic Publishers. Kusch M (2012). sociology of science. Bloor, Collins, Latour. In Brown JR (2012 ed.) Philosophy of science: the key thinkers. London: Continuum. 
Leder D (1990). Clinical interpretation. The hermeneutics of medicine. Theoretical Medicine 11:9-24.

McKenna H, Ashton S, Keeney S (2004). Barriers to evidence based practice in primary care. Journal of advanced Nursing Studies 41:369-78.

McLaughlin J (2001). EBM and risk. Rhetorical resources in the articulation of professional identity. Journal of Management in Medicine 15(5):352-63.

McNeil et al (2013). Interprofessional practice and professional identity threat. Health Sociology Review 22(3), 291-307.

Miles A (1995). Letter: journal of evaluation in clinical practice will start publication in september. BMJ 311(6999):258.

Miles A, Bentley P, Polychronis A, Grey J (1997). Evidence-based medicine: why all the fuss? This is why. Journal of evaluation in clinical practice. 3; 83-6.

Miles A, Bentley P, Polychronis A, Grey J, Price N (1998). Recent progress in health services research: on the need for evidence-based debate. Journal of evaluation in clinical practice. 4:257-65.

Mykhalovskiy E (2003). Evidence-based medicine: ambivalent reading and the clinical recontextualization of science. health 7(3); 331-52.

Norman G (1999). Examining the assumptions of evidence-based medicine. Journal of Evaluation in Clinical Practice 5(2):139-47.

Oakley A (1998). Experimentation and social interventions. A forgotten but important history. BMJ 317:1239-42.

Peacock et al 2014. Dependency denied: Health inequalities in the neo-liberal era. Social Science and Medicine 118, 173-180. 
Petersen A (2013). From bioethics to a sociology of bio-knowledge. Social Science and Medicine 98, 264270.

Popay J, Rogers A and Williams G (1998). Rationale and standards for the systematic review of qualitative literature in health services research. Qualitative Health Research 8(3):341-51.

Rosenberg W and Donald A (1995). Evidence-based medicine: an approach to clinical problem-solving. BMJ 310; 1122-6.

Saarni SI and Gylling HA (2004). Evidence based medicine guidelines: a solution to rationing or politics disguised as science? Journal of Medical Ethics 30:171-5.

Sackett D and Cook R (1994). Understanding clinical trials. British Medical Journal 309(6957):755.

Sackett D and Rosenberg M (1995). On the need for evidence-based medicine. Journal of Public Health Medicine 17(3); 330-4.

Sackett D and Straus S (1998). Finding and applying evidence during clinical rounds. The 'evidence cart'. JAMA 280(15):1336-8.

Sayer A (1999). Realism and social science. London: Sage publications.

Schreiber J and Stern P (2005). A review of the literature on evidence-based practice in physical therapy. The internet journal of allied health sciences and practice 3(4).

Sehon S and Stanley D (2003). A philosophical analysis of the evidence-based medicine debate. BMC Health Service Research 3(14).

Smith et al (2014). A politics of priority setting: Ideas, interests and institutions in healthcare resource allocation. Public Policy and Administration 29(4),331-347.

Smith G and Pell J (2003). Parachute use to prevent death and major trauma related to gravitational challenge: systematic review of randomised controlled trials. British Medical Journal 327:1459-61. 
Thiselton A (2009). Hermeneutics. An introduction. Cambridge: Eerdmans publishing company.

Timmermans (2013). Seven warrants for qualitative health sociology. Social Science and Medicine 77, 1-8.

Tonelli M (1998). The philosophical limits of evidence-based medicine. Academic Medicine 73(12):123440.

Tonelli M (2006). Integrating evidence into clinical practice: an alternative to evidence-based approaches. Journal of evaluation in clinical practice 12(3); 248-56.

Upshur R (1997). Certainty, probability and abduction. Why we should look to CS Peirce rather than Gödel for a theory of clinical reasoning. JECP 3(3):201-6.

Upshur R (1999). Priors and prejudice. Theoretical Medicine and Bioethics 20:319-27.

Upshur R (2000). Seven characteristics of medical evidence. JECP 6(2):93-7.

Upshur R, Van Den Kerkhof E and Goel V (2001). Meaning and measurement. An inclusive model of evidence in healthcare. Journal of Evaluation in Clinical Practice 7(2):91-6.

Upshur R (2002). If not evidence, then what? Or does medicine really need a base? Journal of evaluation in clinical practice $8(2) ; 113-9$.

Upshur R and Tracy C (2004). Legitimacy, authority and hierarchy: critical challenges for evidence-based medicine. Brief treatment and crisis intervention 4(3); 197-204.

Upshur R (2005). Looking for rules in a world of exceptions. Reflections on evidence-based practice. Biology and Medicine 48(4):477-89. 